\title{
In Situ S/TEM Reduction Reaction of Ni-Mo2 C Catalyst for Biomass Conversion
}

Kinga A. Unocic ${ }^{1}$, Jae-Soon Choi ${ }^{1}$, Daniel A. Ruddy ${ }^{2}$, Ce Yang $^{3}$, Jeremy Kropf ${ }^{3}$, Jeffrey Miller ${ }^{4}$, Theodore R. Krause ${ }^{3}$ and Susan Habas ${ }^{2}$

1. Materials Science \& Technology Division, Oak Ridge National Laboratory, Oak Ridge, TN, USA.

2. National Bioenergy Center, National Renewable Energy Laboratory, Golden, CO, USA.

3. Chemical Sciences and Engineering, Argonne National Laboratory, Argonne, IL, USA.

4. Chemical Engineering, Purdue University, West Lafayette, IN, USA.

Increasing interest exists in renewable energy sources to replace fossil fuels. Biomass has a great potential for chemical and fuel production, for example, via fast pyrolysis integrated with hydrotreating [1]. Due to the poor quality of the raw fast pyrolysis bio-oil and lack of effective hydrotreating catalysts for raw pyrolysis oil, it is important to understand and develop hydrotreating (e.g., hydrodeoxygenation) catalysts whose performance (e.g. selectivity, activity, stability) is optimized for biomass conversion processes. Molybdenum based carbides are promising catalysts for biomass conversion processes. Further, modifying the catalysts via metal doping (e.g., $\mathrm{Ni}$ ) can not only increase metal/acid site ratios on the carbide surface but can also enhance stability against oxidation. The aim of this research is to better understand the roles of $\mathrm{Ni}$ species that are incorporated into molybdenum carbides using advanced characterization techniques including X-ray absorption spectroscopy (XAS), high-resolution and in situ scanning transmission electron microscopy (S/TEM).

In situ closed gas cell microscopy can be utilized to study a range of material systems in response to temperatures up to $1000^{\circ} \mathrm{C}$ and pressures up to $1 \mathrm{~atm}$ within a reactive gas environment, which was used here to study the structural and chemical changes of $\mathrm{Ni}-\mathrm{Mo}_{2} \mathrm{C}$ catalysts. The $\mathrm{Ni}-\mathrm{Mo}_{2} \mathrm{C}$ catalyst was prepared via carburization of $\mathrm{Ni}-\mathrm{MoO}_{3}$ beads with carburizing gas $\left(15 \% \mathrm{CH}_{4} / \mathrm{H}_{2}\right)$. The beads were heated to $700^{\circ} \mathrm{C}$ and held for 1 hour under $15 \% \mathrm{CH}_{4} / \mathrm{H}_{2}$ [2]. The low-resolution dark field S/TEM image (Figure 1a) shows the porous structure of the fresh, passivated $\mathrm{NiMo}_{2} \mathrm{C}$ catalyst and the high-resolution image in Figure $1 \mathrm{~b}$ indicates that the material is highly crystalline without any significant amorphous surface layer. For the in situ STEM experiments, the fresh Ni-Mo $\mathrm{M}_{2} \mathrm{C}$ catalysts were crushed in ethanol to decrease the size scale such that it will fit within the $5 \mu \mathrm{m}$ gap within the gas-cell [3]. A droplet of the suspension was placed on the silicon nitride window of a Protochips ${ }^{\mathrm{TM}} \mathrm{E}$-chip heater chip. The Protochips Atmosphere ${ }^{\mathrm{TM}}$ gas reaction system was then used for the in situ STEM experiments, which were conducted using an aberration-corrected JEOL 2200FS operated at 200kV. The gas-cell was flushed three times with nitrogen from 300 to 0.5 Torr to ensure there was no $\mathrm{O}_{2}$ present in the system. The pressure was then set to 300 Torr and the gas-cell was filled with $100 \% \mathrm{H}_{2}$. Temperature was brought from room temperature to $500^{\circ} \mathrm{C}$ under flowing $100 \% \mathrm{H}_{2}$ at $5^{\circ} \mathrm{C} / \mathrm{min}$. No significant change in the morphology of the catalyst particles was observed while the temperature was increasing up to $500^{\circ} \mathrm{C}$. The $\mathrm{Ni}-\mathrm{Mo}_{2} \mathrm{C}$ was stable under reducing conditions at $500^{\circ} \mathrm{C}$ (Figure 2), which is consistent with other measurements (XRD, surface area measurement, surface reduction with gas analysis). Energy dispersive X-ray spectroscopy (EDS) elemental analysis after reaching $500^{\circ} \mathrm{C}$ confirmed that the catalyst was primarily associated with Mo and uniform distribution of $\mathrm{Ni}$ (Figure 3). There was no visible change in the composition distribution of both elements before and after reaction, thereby indicating this catalyst is stable under reacting conditions. These results show validation of in situ S/TEM capabilities that enable future identification of active sites and catalyst regeneration procedures [4]. 


\section{References:}

[1] H Wang, J Male, Y Wang. ACS Catal. 3 (2013) p. 1047.

[2] J S Lee, S T Oyama, M Boudart, J. Catalysis. 106 (1987), p. 125.

[3] K A Unocic et al, Oxid. Metals 88 (2017), p. 495.

[4] This work was performed in collaboration with ChemCatBio, a member of the Energy Materials Network (EMN), and supported by the U.S. DOE Bioenergy Technology Office under Contract no DE-AC05-00OR22725 (ORNL), Contract no. DE-AC36-08-GO28308 (NREL), and Contract no. DE-AC02-06CH11357 (ANL). Microscopy performed as part of a user project at the Center for Nanophase Materials Sciences (CNMS), which is a U.S. DOE Office of Science User Facility.
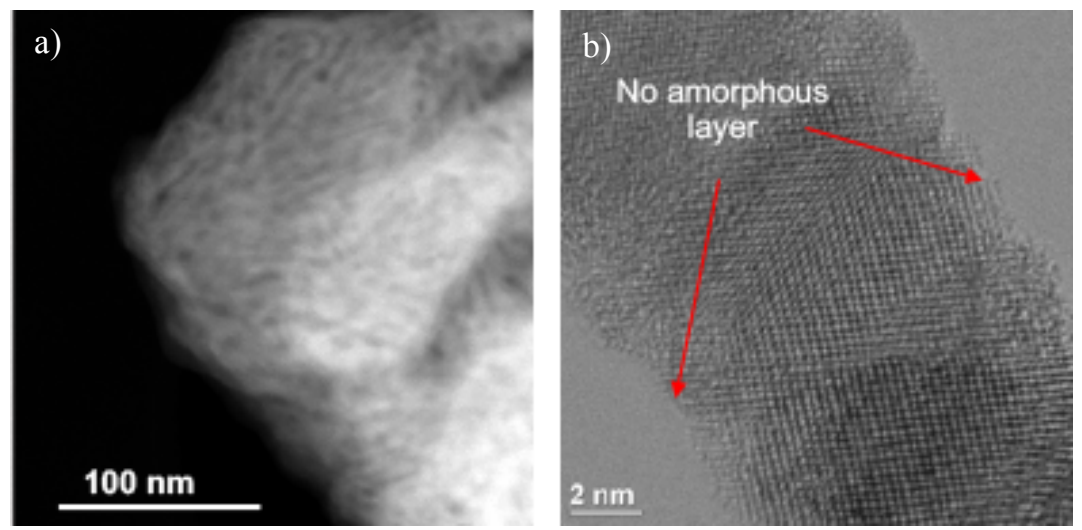

Figure 1. a) HAADF-STEM and b) high resolution BFSTEM images showing the structure of fresh Ni- $\mathrm{Mo}_{2} \mathrm{C}$.
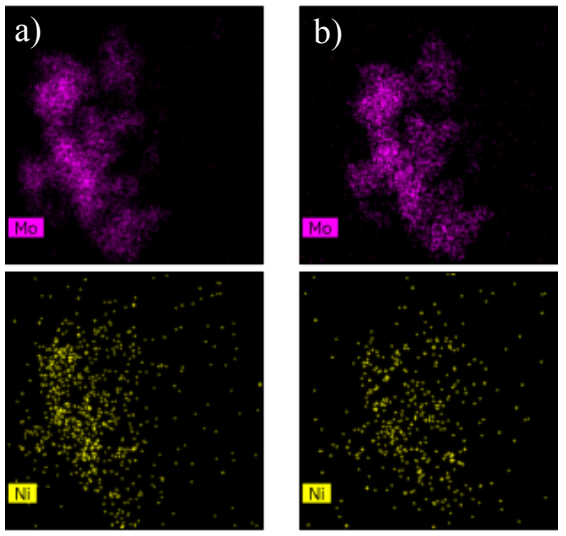

Figure 3. Mo and Ni elemental maps for the fresh passivated $\mathrm{Ni}-\mathrm{Mo}_{2} \mathrm{C}$ catalyst shown in Figure 2 at a) room temperature in vacuum and b) at $500^{\circ} \mathrm{C}$ in flowing $100 \% \mathrm{H}_{2}$ and 300 Torr using in situ $\mathrm{S} / \mathrm{TEM}$.

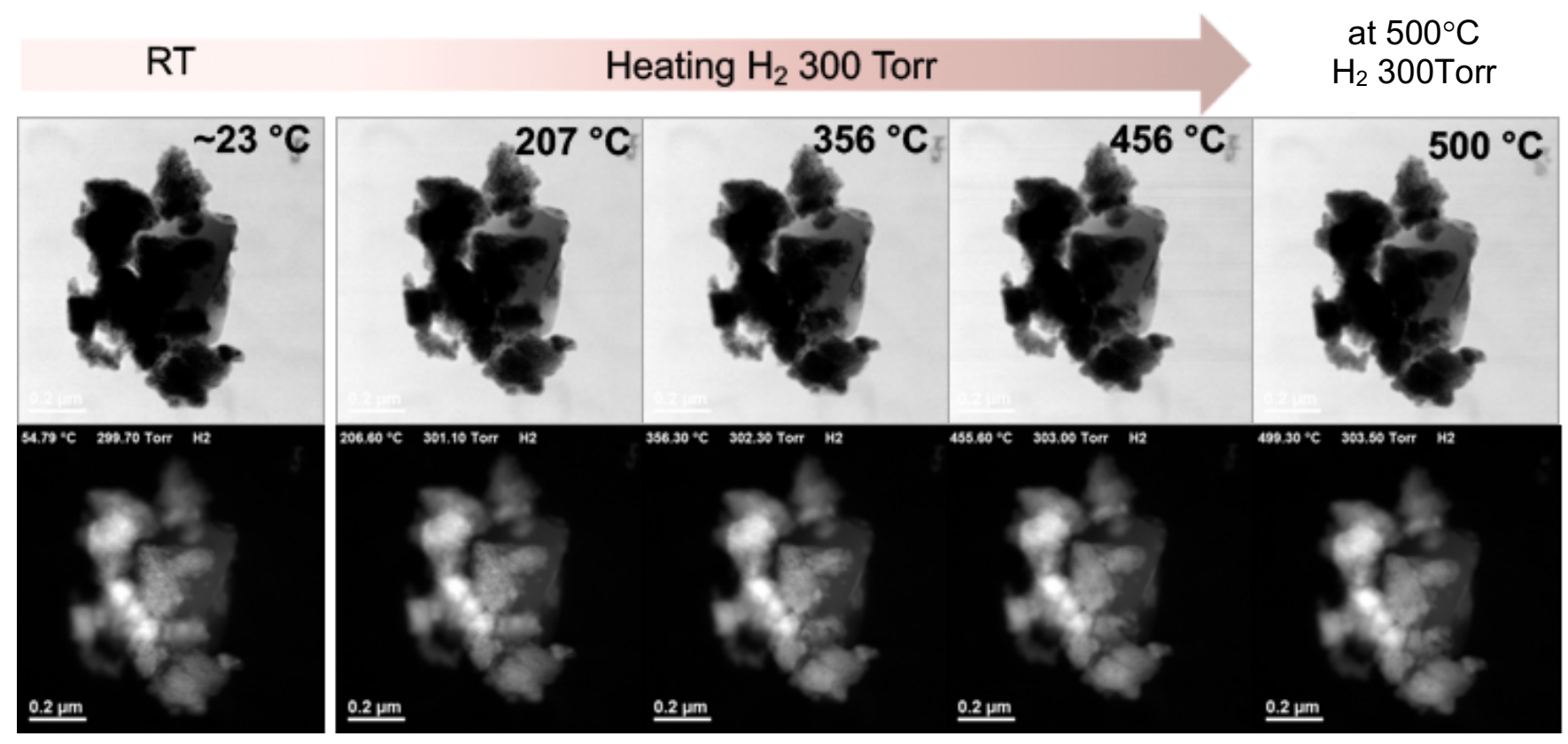

Figure 2. Time-lapsed HAADF-STEM and simultaneously acquired BF-STEM images showing behavior of fresh $\mathrm{Ni}-\mathrm{Mo}_{2} \mathrm{C}$ under heating to $500^{\circ} \mathrm{C}$ in flowing $100 \% \mathrm{H}_{2}$ at 300 Torr. 